\title{
Defining Allowable Physical Property Variations for High Accurate Measurements on
} Polymer Parts.

Mohammadi, Ali; Sonne, Mads Rostgaard; Madruga, Daniel González; De Chiffre, Leonardo; Hattel, Jesper Henri

Published in:

AIP Conference Proceedings

Link to article, DOI:

$10.1063 / 1.4951804$

Publication date:

2015

Document Version

Publisher's PDF, also known as Version of record

Link back to DTU Orbit

Citation (APA):

Mohammadi, A., Sonne, M. R., Madruga, D. G., De Chiffre, L., \& Hattel, J. H. (2015). Defining Allowable Physical Property Variations for High Accurate Measurements on Polymer Parts. In AlP Conference Proceedings (Vol. 1738). AIP Publishing LLC. A I P Conference Proceedings Series Vol. 1738 https://doi.org/10.1063/1.4951804

\section{General rights}

Copyright and moral rights for the publications made accessible in the public portal are retained by the authors and/or other copyright owners and it is a condition of accessing publications that users recognise and abide by the legal requirements associated with these rights.

- Users may download and print one copy of any publication from the public portal for the purpose of private study or research.

- You may not further distribute the material or use it for any profit-making activity or commercial gain

- You may freely distribute the URL identifying the publication in the public portal 
Defining allowable physical property variations for high accurate measurements on polymer parts

A. Mohammadi, M. R. Sonne, D. G. Madruga, L. De Chiffre, and J. H. Hattel

Citation: AIP Conference Proceedings 1738, 030048 (2016); doi: 10.1063/1.4951804

View online: http://dx.doi.org/10.1063/1.4951804

View Table of Contents: http://aip.scitation.org/toc/apc/1738/1

Published by the American Institute of Physics 


\title{
Defining Allowable Physical Property Variations for High Accurate Measurements on Polymer Parts
}

\author{
A. Mohammadi, M.R. Sonne, D.G. Madruga, L. De Chiffre and J.H. Hattel \\ Department of Mechanical Engineering, Technical University of Denmark, Nils Koppels Allé, 2800 Kgs. Lyngby, \\ Denmark.
}

\begin{abstract}
Measurement conditions and material properties have a significant impact on the dimensions of a part, especially for polymers parts. Temperature variation causes part deformations that increase the uncertainty of the measurement process. Current industrial tolerances of a few micrometres demand high accurate measurements in non-controlled ambient. Most of polymer parts are manufactured by injection moulding and their inspection is carried out after stabilization, around 200 hours. The overall goal of this work is to reach $\pm 5 \mu \mathrm{m}$ in uncertainty measurements a polymer products which is a challenge in today 's production and metrology environments. The residual deformations in polymer products at room temperature after injection molding are important when micrometer accuracy needs to be achieved. Numerical modelling can give a valuable insight to what is happening in the polymer during cooling down after injection molding. In order to obtain accurate simulations, accurate inputs to the model are crucial. In reality however, the material and physical properties will have some variations. Although these variations may be small, they can act as a source of uncertainty for the measurement. In this paper, we investigated how big the variation in material and physical properties are allowed in order to reach the $5 \mu \mathrm{m}$ target on the uncertainty.
\end{abstract}

Keywords: Finite Element Analysis, Thermo-mechanical Model, Uncertainty Budgeting

PACS: 46.70.-P

\section{INTRODUCTION}

Quality control of a manufactured product is money consuming, and especially when the requirements for accuracy increase the cost increases as well. Therefore, a procedure to reduce the number of necessary measurements without losing the accuracy of the products is always appreciated. In the case of polymer products the case is even worse, since deformations occur at room temperature several days or weeks after production because of creep, shrinkage and moisture phenomena within the part [1]. In order to tackle these phenomena, more measurements of the product are needed which is costly and time consuming.

Creep, shrinkage and moisture are very much related to the thermal conditions in the polymer material. Hence, a numerical model which considers heat transfer and its relation to the dimensions of the object can provide valuable information for the measurement procedure and lead to a reduced number of measurements.

The simulation is affected by variation in material properties such as heat conductivity, density, specific heat, thermal expansion coefficient and physical properties, such as temperature and heat transfer to the surrounding air. This variation should be considered because it is an inseparable part of each experiment. Hess et al tried to improve the design of thin plate by considering uncertainty in material properties, geometric and load [2]. Urquhart and Brown considered uncertainty in heat transfer data in their investigation to predict processing condition and reduce the amount of scrap in polymer parts [3].

In this paper, after a short introduction to the applied theory, a procedure for thermo-mechanical simulations is defined and verified by experimental result from length variations in an aluminum block. Later, the simulations are conducted for a polymer part by changing the material to the polymer Acrylic Butadiene Styrene (ABS). Uncertainty budgeting is investigated for heat conductivity, density, specific heat, thermal expansion coefficient of the ABS material, initial temperature of the object and heat transfer coefficient to the air. Finally, results and discussion conclude the paper. 


\section{THEORY}

Imagine a specimen that is heated up to a temperature above room temperature. When it is cooled down, the heat flows from the specimen into the air. In this study, conduction is considered as the main source of heat transfer in the model with appropriate boundary condition which is driven by convection. Heat conduction equation is

$$
\rho c_{p} \frac{\partial T}{\partial t}=k\left(\frac{\partial^{2} T}{\partial x^{2}}+\frac{\partial^{2} T}{\partial y^{2}}+\frac{\partial^{2} T}{\partial z^{2}}\right) .
$$

Where $T$ is temperature, $\rho$ is density, $c_{p}$ is specific heat, $k$ is thermal conductivity, $t$ is time and $x, y, z$ are space coordinates in a Cartesian coordinate system.

Newton's law of cooling is govern by

$$
\frac{q}{A}=-h_{a}\left(T_{s}-T_{\infty}\right)
$$

Where $q$ is heat flux, $T_{s}$ is the surface temperature of the aluminum block, $T_{\infty}$ is the temperature of air, $h_{a}$ is heat transfer coefficient from the gauge block surface to the air and $A$ is the surface area. The length variation will be found from calculations of the thermal strain $\varepsilon^{\text {th }}$, as this is the only contribution to the total strain $\varepsilon^{\text {tot }}$ for these applications

$$
\varepsilon^{t o t}=\varepsilon^{t h}=\int_{T_{\infty}}^{T_{s}} \alpha d t
$$

where $\alpha$ is thermal expansion coefficient. In metrology, the uncertainty of measurements is calculated as the addition of the errors in the length caused by different influence factors such as material properties uncertainty, measuring conditions variation, heat transfer variation, etc.. Uncertainty of measurements is calculated by uncertainty budgeting [4] and [5].

$$
\begin{gathered}
\bar{x}=\frac{\sum_{i=1}^{N} x_{i}}{N} \\
u_{s p}=\sqrt{\frac{1}{N(N-1)} \sum_{i=1}^{N}\left(x_{i}-\bar{x}\right)^{2}}
\end{gathered}
$$

Where $u_{s p}$ is the standard uncertainty of the simulation procedure, $x_{i}$ is the samples value, $\bar{x}$ is average and $N$ is the number of samples. Here, this value is the number of simulations with different physical properties.

\section{NUMERICAL MODEL}

Verification of the numerical model is conducted by a sequentially coupled thermo-mechanical model of an aluminum block. The simulation consists of three parts:

1. Heat conduction through the aluminum block

2. Heat transfer through the air (Fig. 1(a))

3. Length variation of the aluminum gauge block(Fig. 1(b))

Two graphs will be obtained, one for the cooling with respect to time (Fig. 1(a)), another one for the length variation as a function of time (Fig. 1(b)). The length variation was set to zero at time zero. The commercial software ABAQUS is used for this purpose. In the experimental study the length variation of a block with dimensions of $(100 \times 35 \times 9) \mathrm{mm}$ is determined when it is cooled down from $25^{\circ} \mathrm{C}$ to approximately $20^{\circ} \mathrm{C}$ [6]. Hence, the cooling curve (Fig. 1(a) dash line) and length variation curve (Fig. 1(b) dash line) are available from the experiment. In the modelling it is needed to estimate the heat transfer coefficient to the air $\left(h_{a}\right)$; hence the cooling curves from the experiment and simulation are compared with each other (Fig. 1(a)). The heat transfer coefficient is obtained based on the minimum root mean square error between the experimental and simulated temperature curves in Fig. 1(a). For verifying the obtained $h_{a}$ value, the length variation graphs from experiment and simulation are compared as seen in Fig. 1(b). It is observed that there is a good correlation between the length variation graphs as well. So it is evaluated that the modelling and its boundary condition are done correctly. 

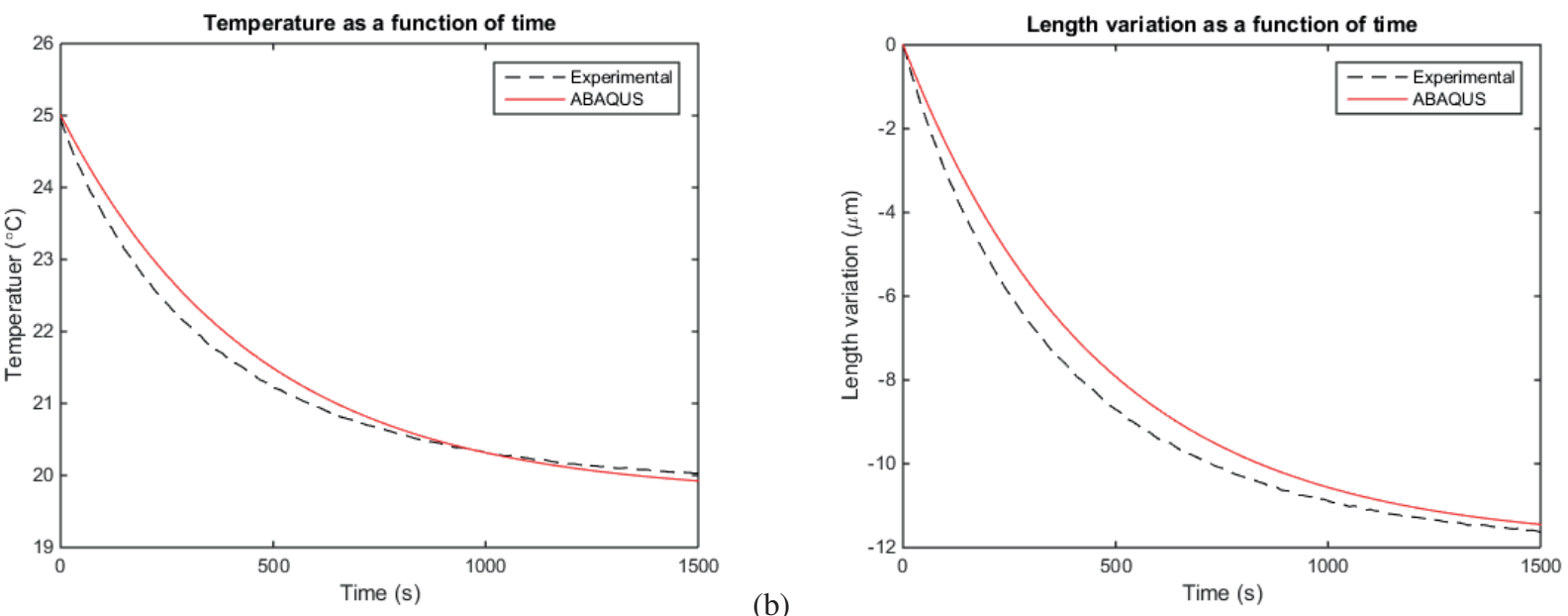

(a)

(b)

FIGURE 1. (a)Comparison of the transient temperature evolution in the center point of the aluminum block from experiment and simulation (b) Comparison of the length variation as a function of time from experiment and simulation.

TABLE 1. Length variation dependently on variation of material properties and physical parameters of a ABS polymer specimen.

\begin{tabular}{c|c|c|c|c}
\hline Name & symbol & dimension & value & length variation $(\mu \mathrm{m})$ \\
\hline Thermal expansion & $\alpha$ & $\frac{e-6}{K}$ & $67.5 \pm 24.5$ & $12.75 \pm 1.145$ \\
\hline Initial temperature & $T_{0}$ & ${ }^{\circ} \mathrm{C}$ & $25 \pm 1.4$ & $9.44 \pm 0.621$ \\
\hline Specific heat & $c_{p}$ & $\frac{J}{\mathrm{kgk}}$ & $1467 \pm 291$ & $9.40 \pm 0.012$ \\
\hline Heat transfer Coef. to the air & $h_{a}$ & $\frac{W}{\mathrm{~m}^{2} K}$ & $18 \pm 2$ & $9.44 \pm 0.003$ \\
\hline Thermal conductivity & $k$ & $\frac{W}{\mathrm{mk}}$ & $0.18 \pm 0.014$ & $9.44 \pm 0.001$ \\
\hline Density & $\rho$ & $\frac{\mathrm{kg}}{\mathrm{kgm}^{3}}$ & $1070 \pm 14$ & $9.44 \pm 0.000$ \\
\hline
\end{tabular}

\section{UNCERTAINTY BUDGETING}

The numerical model is now used for uncertainty budgeting of the length variation on the ABS polymer specimen with dimensions $(32 \times 16 \times 10) \mathrm{mm}$. In the simulation ABS is assumed to be isotropic. The material properties are changed within a limited range obtained from minimum and maximum values found in literature [7] with an upper and lower tolerance. Then, length variation in both ends of the interval is extracted from the simulation and the uncertainty is calculated by the Eq. 5. The results are shown in table 1.

\section{CONCLUSION}

It is seen from table 1, that the thermal expansion coefficient and initial temperature of the polymer specimen have higher uncertainty value $(1 \sigma$ level). Hence, these two parameters can influence on the uncertainty measurement of length more than others which is of course expected because thermal strain is the main source of length variation here. That means the allowable variation for these two parameters must not to be that much wide for a real experiment. It is worth to say, for any arbitrary case, measurement uncertainty in design specification with the aid of this kind of simulation can define allowable variation in material and physical properties to minimize the source of error in high accurate measurement. However in this simulation, creep, moisture and shrinkage are not considered and they play an important role of the final shape of a polymer part. Moreover, in industrial cases, the geometry is more complex than in this study which can limit the allowable range of physical parameters more than in this analysis. Uncertainty budgeting 
consideration improves the simulation by taking into account the variation in material and physical properties which makes simulation closer to the real behaviour of the part. Here, a simple analysis is addressed to verify the procedure of considering uncertainty in modelling. Evaluating this procedure confirms that we can use this procedure for a complex model in future.

\section{ACKNOWLEDGMENTS}

This work has been supported by the Innovation Fund Denmark through the project Accurate Manufacture which is highly acknowledged.

\section{REFERENCES}

1. L. D. Chiffre, D. Gonzalez-Madruga, G. D. Costa, L. Neves, and I. Jespersen, "Dimensional measurements with submicrometer uncertainty in production environment," in 15th International Conference and Exhibition of the European Society for Precision Engineering and Nanotechnology, edited by R. Leach, euspen, Leuven, Belgium, 2015, pp. 131-132.

2. P. Hess, D. Bruchman, I. A. Assakkaf, and B. M. Ayyub, NAV. ENG. J. 114, 139-166 (2002).

3. J. M. Urquhart, and C. S. Brown, The effect of uncertainty in heat transfer data on the simulation of polymer processing, Tech. rep., National Physical Laboratory (2004).

4. ISO, Guide to the expression of uncertainty in measurement, (GUM), International Organization for Standardization, Geneva, Switzerland (2008).

5. ISO, Geometrical Product Specification (GPS) - Inspection by measurement of workpieces and measuring equipment - Part 2: Guidance for the estimation of uncertainty in GPS measurement, in calibration of measuring equipment and in product verification, ISO 14253-2:2011, International Organization for Standardization, Geneva, Switzerland (2011).

6. L. D. Chiffre, M. Gudnason, and D. Gonzalez-Madruga, "Dimensional measurements with submicrometer uncertainty in production environment," in 15th International Conference and Exhibition of the European Society for Precision Engineering and Nanotechnology, edited by R. Leach, euspen, Leuven, Belgium, 2015, pp. 163-164.

7. The free and independent online materials properties resource (2015), URL http://www . matbase.com. 